\title{
ENCONTRABILIDADE DA INFORMAÇÃO E VIDEOATIVISMO: UMA ANÁLISE DO ATRIBUTO FOLKSONOMIA NO YOUTUBE
}

\section{FINDABILITY AND VIDEOTIVISM: AN ANALYSIS OF THE FOLKSONOMY ATTRIBUTE ON YOUTUBE}

Jéssica Amorim do Nascimento ${ }^{1}$

Angela Maria Grossi de Carvalho²

\begin{abstract}
RESUMO
Introdução: As tecnologias digitais associadas à mobilidade e à web social transformaram as relações sociais em diversas esferas. Os ambientes têm se tornado cada dia mais cooperativos e a massa de informação depositada e compartilhada diariamente cresce de acordo com o número de usuários - o que modificou a relação que temos com a forma de compartilhar as informações na web, bem como a forma que produzimos ou realizamos qualquer tipo de manifestação social. Objetivo: De acordo com essa premissa, este artigo apresenta um estudo que buscou analisar a folksonomia - atributo da Encontrabilidade da Informação de Vechiato e Vidotti (2014), que analisa a etiquetagem social - partindo dos usuários. Metodologia: A análise foi realizada no ambiente YouTube, coletando as informações sobre os protestos do dia 17 de julho de 2013 e identificando o conteúdo de videoativismo para compreender de que forma 0 atributo presta contribuição para a aplicação da Encontrabilidade da Informação. Resultado: No YouTube, são apresentados aproximadamente 145 mil resultados com a busca "17 de junho de 2013", e em sua maioria, não pertencem à mídia tradicional - são propostas videoativistas. Destes, após análise de acordo com a metodologia de observação, o número foi reduzido para 8 páginas de conteúdo relevantes. Conclusão: Foi possível utilizar a folksonomia no momento da publicação do vídeo. Com a busca "17 de junho de 2013", e o resultado foi 145 mil vídeos. Após utilização da informação, este número mudou para 159 vídeos que possuem real ligação com o tema proposto - que classifica o atributo folksonomia como bastante relevante para a Encontrabilidade no ambiente estudado.
\end{abstract}

Descritores: Encontrabilidade da Informação. Folksonomia. Videoativismo.

\footnotetext{
${ }^{1}$ Mestranda do Programa de Pós-Graduação em Ciência da Informação - Unesp Marília. E-mail:jess.duna@gmail.com

${ }^{2}$ Doutora em Ciência da Informação pela Universidade Estadual Paulista Júlio de Mesquita Filho (Unesp), Campus de Marília. Professora do Programa de Pós-Graduação em Ciência da Informação pela Universidade Estadual Paulista Júlio de Mesquita Filho (Unesp), Marilia. Email: angela@carvalho.jor.br
} 


\section{INTRODUÇÃO}

A preocupação com a estruturação, representação e organização de todos os conteúdos informacionais produzidos acompanha o desenvolvimento cultural da humanidade há séculos. Contudo, é atualidade, com as rupturas de barreiras entre tempo e espaço que as Tecnologias de Informação e Comunicação (TIC) ganham destaque, recebendo uma maior atenção e importância, principalmente após o surgimento da Internet e de seu ambiente World Wide Web (WWW).

As tecnologias aplicadas no cotidiano, interferem nos modos de produzir e acessar informação e propiciam o surgimento de um novo sistema hibridizado em que homens e máquinas, modificam o fluxo informacional, pelas suas formas de interação, realizando aumentos exponenciais.

Nos últimos anos, os avanços tecnológicos ampliaram as possibilidades de recuperação, de acesso, de uso e de apropriação da informação a partir da ligação e do relacionamento entre dados e informações em diferentes dispositivos e sistemas, além da colaboração dos sujeitos informacionais na produção e na organização da informação e do conhecimento em ambientes informacionais digitais.

Nesse sentido, Wurman (2005) considera que o produto da Era Digital é a informação e que seu meio de transporte é a Internet,

[...] o que significa que a informação errada pode ser transmitida tão facilmente quanto a certa, causando o que chamamos de desinformação. $O$ apertar de um botão pode espalhar informações errôneas sobre você pelo mundo afora. (WURMAN, 2005, p. 13).

Reis (2012, p. 1) completa afirmando que:

O fenômeno das redes sociais, do trabalho colaborativo e a presença dos media online em muito contribuem para o crescimento exponencial da informação criada e disponibilizada a cada instante. Deste modo, o ser humano está hoje exposto diariamente a uma enorme quantidade de informação, proveniente das mais diversas fontes, com a qual não consegue lidar. Por outro lado, muita da informação gerada não interessa de igual forma a todas as pessoas. 
Assim, pode-se considerar que tais fatores podem resultar na denominada ansiedade informacional, definida por Wurman (2003, p. 38) como:

O resultado da distância cada vez maior entre o que compreendemos e o que achamos que deveríamos compreender. É o buraco negro que existe entre dados e conhecimento, e ocorre quando a informação não nos diz o que queremos ou precisamos saber.

Considerando a informação como objeto de trabalho do profissional da informação, diante do fenômeno de crescimento informacional, são necessários estudos que abranjam tanto os ambientes informacionais com os quais os usuários interagem, como a forma com a qual é realizada a descrição dessas informações compartilhadas.

Neste cenário, Robredo (2008, p. 131) destaca que a Ciência da Informação (Cl), cuja pedra angular é a representação e a organização da informação e do conhecimento, dirige seu olhar para a Arquitetura da Informação, campo emergente, considerando-a propiciadora e facilitadora da passagem da informação para o conhecimento e a compreensão do indivíduo atuante no espaço contemporâneo das Tecnologias de Informação e Comunicação.

Partindo da afirmação de que a Arquitetura da Informação Digital almeja o acesso fácil e satisfatório de ambientes informacionais digitais pelos seus usuários, é preciso verificar se a estruturação das coleções, o acesso às informações e o próprio conteúdo em repositórios estão sendo customizados de maneira a atender seus usuários potenciais. (RIBEIRO; VIDOTTI, 2009, p. 114).

A partir da premissa da Arquitetura da Informação, surge a Encontrabilidade da Informação, termo indicado por Vechiato e Vidotti (2014a) com a proposta de incorporar os estudos no campo da Ciência da Informação partindo da investigação de aspectos epistemológicos e teóricos que favoreçam o encontro das informações na Web, utilizando seus atributos, visto que Findability é o grande problema dos web sites e a Arquitetura da Informação é a solução. (MORVILLE, 2005).

Para realização desta pesquisa, analisou-se o elemento folksonomia, buscando compreender como este pode influenciar na busca e recuperação de produções videoativistas dos protestos de junho de 2013.

As folksonomias estão relacionadas à organização social da informação que propicia ao sujeito a classificação de recursos informacionais, bem como encontrar a informação por meio da navegação (uma nuvem de tags, por exemplo) ou dos mecanismos de bu0sca, ampliando as possibilidades de acesso. São utilizadas 
em estruturas de organização bottom-up. Quando associadas aos vocabulários controlados e às tecnologias semânticas, potencializam as possibilidades de constituição de uma Web Pragmática. (VECHIATO; VIDOTTI, 2014b, p. 50).

Com essa análise, busca-se solucionar a questão de como o atributo da folksonomia pode influenciar na aplicação da Encontrabilidade da Informação, utilizando como método a observação de conteúdo no ambiente YouTube, ao ponto que a folksonomia é considerada a antítese ao termo taxonomia, tendo como principal característica a criação de tags com função de descritor a partir da linguagem dos usuários.

\section{ENCONTRABILIDADE DA INFORMAÇÃO}

Para Vechiato e Vidotti (2014a, p. 164), a Encontrabilidade da Informação "[...] sustenta-se fundamentalmente na interseção entre as funcionalidades de um ambiente informacional e as características dos sujeitos informacionais."

A contribuição deste conceito está principalmente no fato de considerar as características dos sujeitos informacionais como um componente indispensável para o projeto de ambientes e sistemas de informação.

Para a sua aplicação, são necessários alguns atributos: Taxonomias navegacionais, Instrumentos de controle terminológico, Folksonomias, Metadados, Mediação, Affordances, Wayfinding, descoberta de informações, Acessibilidade e Usabilidade, Intencionalidade, Mobilidade, Convergência e Ubiquidade.

\subsection{Folksonomias}

Folksonomia - termo criado por Thomas Van der Wal (2005), designa formas de organizar e compartilhar os conteúdos disponíveis na Internet através da etiquetagem (tagging).

Segundo Catarino e Baptista (2007, p. [04]), a Folksonomia destaca os seguintes fatores:

a) é resultado de uma indexação livre do próprio usuário do recurso;

b) objetiva a recuperação a posteriori da informação e

c) é desenvolvida num ambiente aberto que possibilita o compartilhamento e, mesmo, em alguns casos, a sua construção conjunta. 
O resultado da colaboração social gera um conjunto de marcações conhecidas como folksonomia, que representa uma prática de categorização colaborativa usando palavras-chave (tags) livremente escolhidas pelos usuários (MIKA, 2007).

Tsui et al. (2010) definem a folksonomia como o produto final de um processo pelo qual muitos usuários adicionam metadados na forma de palavras-chave ou etiquetas para compartilhar conteúdo. Considera-se que a mesma representa uma mixagem dessas práticas com a inovação do ambiente colaborativo propiciado pelas redes sociais.

De acordo com Blattmann e Silva (2007, p. 207), a folksonomia é uma "[...] forma relacional de categorizar e classificar informações disponíveis na Web sejam elas representadas por meio de textos, imagens, áudio, vídeo ou qualquer outro formato." Dessa forma a categorização de forma hierárquica e centralizada deixa seu lugar para que o usuário escolha palavras-chave (conhecidas como "tags") para classificar a informação.

Para Vechiato e Vidotti (2014a), no âmbito da Encontrabilidade da Informação, as folksonomias estão relacionadas à organização social da informação e propiciam ao sujeito a classificação de recursos informacionais, bem como encontrar a informação por meio da navegação. São utilizadas em estruturas de organização bottom-up.

Segundo Assis e Moura (2016), a folksonomia poderia ser colocada como uma inovação, potencializadora do uso das redes sociais - tanto na organização como no compartilhamento dos recursos informacionais.

Para Farooq (2007), a unidade básica de informação nas folksonomias é uma tríade constituída por: sujeito - conteúdo - tag. Esses três elementos caracterizam os ambientes colaborativos que as utilizam como redes complexas (SHEN; WU, 2005), de maneira que as redes que se configuram nesses contextos podem ser analisadas sob distintos aspectos, dentre os quais se destacam: sociais (redes de atores sociais) e semânticos (redes de conceitos).

A associação de etiquetas de texto em recursos digitais por usuários é amplamente utilizada como método de indexação em plataformas de vídeos. Essa ação de marcação pelos usuários é comum de ser encontrada em mídias sociais com o objetivo de criar metadados e ligações que poderão ser úteis para a 
classificação, navegação, recomendação ou recuperação de conteúdo (LOHMANN; DÍAZ, 2012).

Essas ligações levam os usuários a encontrar informações similares as informações que já estão sendo apresentadas. Dessa forma, a utilização da folksonomia, no lugar de uma estrutura hierárquica e pré-organizada acaba por atrair mais usuários para as mídias sociais.

\section{WEB E VIDEOATIVISMO}

Com o advento das tecnologias digitais, dos dispositivos móveis e das mídias sociais conectadas em uma rede global por meio da internet, o videoativismo ganhou um impulso. A facilidade na produção e distribuição das obras audiovisuais proporcionou um grande aumento no número de vídeos produzidos e mudou os paradigmas das práticas videoativistas.

Em uma sociedade digital, a câmera, um telefone móvel ou qualquer outro objeto capaz de registrar áudio e vídeo de forma imediata operam como ferramentas políticas; armas que cabem em nossos bolsos e que são capazes de captar a realidade de olhos que até há pouco tempo permaneciam à margem do sistema tradicional de comunicação. Graças à prática videoativista, adquirem voz grupos que têm sido invisibilizados e excluídos do discurso público dominante que controla as corporações midiáticas. (GARCIA, 2014, p. 136-137 apud DURIGAN, 2016, p. 38).

Segundo Garcia (2014), o conceito de videoativismo pode ser caracterizado como sendo uma prática de reivindicação política. Bardají (2014) afirma que atualmente a produção está estreitamente vinculada às novas tecnologias, pois as possibilidades que têm sido oferecidas favorecem a produção e a divulgação, visto que os equipamentos estão cada dia melhores, bem como os canais na internet que oferecem a chance de divulgação e propagação dos mesmos.

Dessa forma a divulgação e o acesso a esse tipo de informação têm sido democratizados, permitindo que mais usuários estejam ligados ao mesmo tema, uma vez que qualquer usuário, com acesso à Internet, tem a possibilidade de se cadastrar e disponibilizar vídeos para exibição gratuita, as perspectivas de uma possível participação do cidadão na estrutura comunicacional de uma rede global crescem consideravelmente. 
Para tanto, esses grupos se organizam e produzem conteúdos de interesse coletivo, registrando as inquietudes sociais.

Segundo Renó (2015, p. 57, tradução nossa):

O que chama a atenção em tudo isso é a possibilidade de organização e circulação nos meios sociais dos conteúdos produzidos pelo grupo, especialmente em tempo real. Para isso, as células jornalísticas, como são denominados por alguns deles, adotam uma tecnologia simples e econômica: um smartphone com conexão à internet e conectado a um computador portátil guardado em uma mochila. O computador serve para garantir melhor capacidade de bateria no smartphone (que trabalha horas sem carregar). Por outro lado, o smartphone serve para registrar fotos (que são publicadas em tempo real) e vídeos, transmitidos em tempo real por aplicações grátis, como o Ustream.

Com isso, essa forma de protesto comunicacional audiovisual se insere num modelo de ativismo que incorpora tecnologia, arte e comunidades para mobilizar os indivíduos, fazendo com que essas "[...] modalidades comunicativas, colaborativas e expressivas tornam-se, em si mesmas, práticas de resistência, capazes de estabelecer novos arranjos subjetivos, novos modos de ser e estar no mundo." (MAZETTI, 2008, p. 106).

Neste cenário, os vídeos com conteúdo ativistas, usualmente, primam pelo registro dos acontecimentos da forma mais natural possível, com a espontaneidade ao conduzir a câmera e pouca ou nenhuma preocupação estética, já que o compromisso ao se produzir o conteúdo é com a mensagem, e não o visual.

\section{ANÁLISE DO ATRIBUTO FOLKSONOMIA: PROTESTOS 17 DE JUNHO DE 2013}

Nos últimos anos, especialmente na última década, a intensificação do uso das mídias sociais digitais e a popularização de dispositivos móveis, transformaram paradigmas no campo das Tecnologias de Informação e Comunicação. No Brasil, esse cenário foi representado, principalmente, pelo dia 17 de junho de 2013: milhares de pessoas foram às ruas em aproximadamente 350 cidades, causando perplexidade nos representantes políticos e um grande impacto em todo o país, além de uma repercussão mundial.

Os protestos, que tiveram início devido ao reajuste na tarifa do transporte público em duas das principais capitais do país (São Paulo e Rio de Janeiro), logo 
cresceram e se disseminaram por todo país, propulsionados pelas conexões em rede e pela divulgação das imagens dos movimentos por meio de vídeos populares, que se espalharam nas redes sociais, com a prática do videoativismo.

No website YouTube, são apresentados aproximadamente 145 mil resultados com a busca "17 de junho de 2013", e em sua maioria, são vídeos que não possuem nenhuma ligação com fontes oficiais de notícias ou canais de mídia convencional: foram publicados por usuários comuns, sempre utilizando a sentença em seu título ou descrição.

Figura 1 - Resultados da busca "17 de junho de 2013" no YouTube

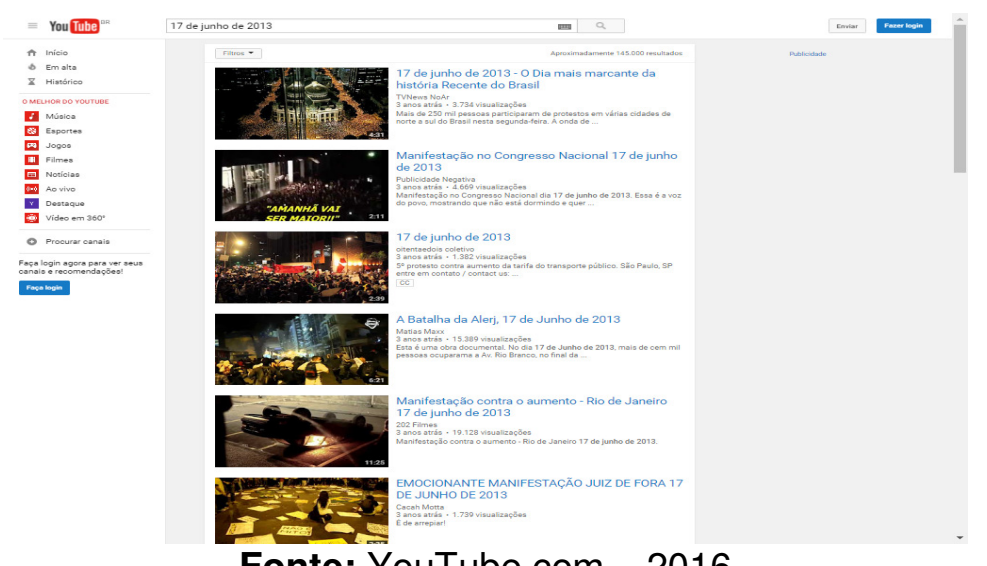

Fonte: YouTube.com - 2016

Os resultados apresentam vídeos postados por diversos usuários, mostrando inúmeros cenários da mesma manifestação. É possível verificar vídeos que tratam sobre o mesmo assunto, unidos por meio de um título em comum, ainda que seu conteúdo possa abranger diversas cidades e estados, como é o caso dos vídeos "Manifestação contra o aumento - Rio de Janeiro 17 de junho de 2013" (figura 2) e “Emocionante manifestação Juiz de Fora 17 de junho de 2013” (figura 3). 
Figura 2 - Manifestação contra o aumento - Rio de Janeiro 17 de junho de 2013

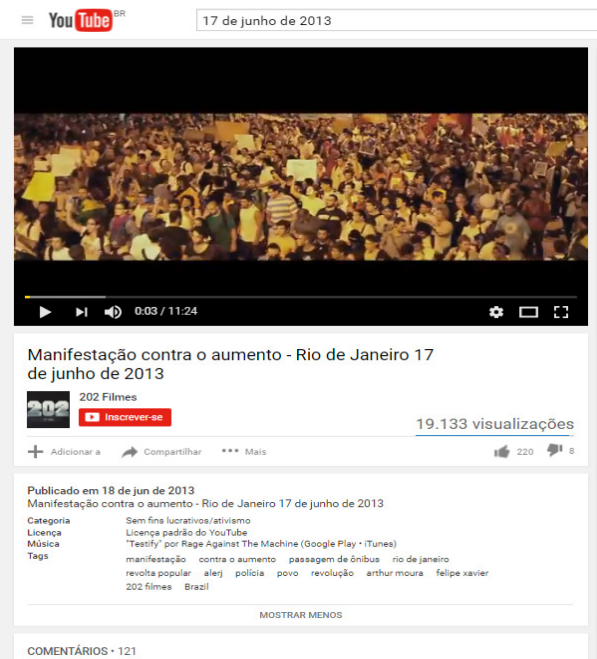

Fonte: YouTube.com - 2016

Figura 3 - Emocionante manifestação Juiz de Fora 17 de junho de 2013

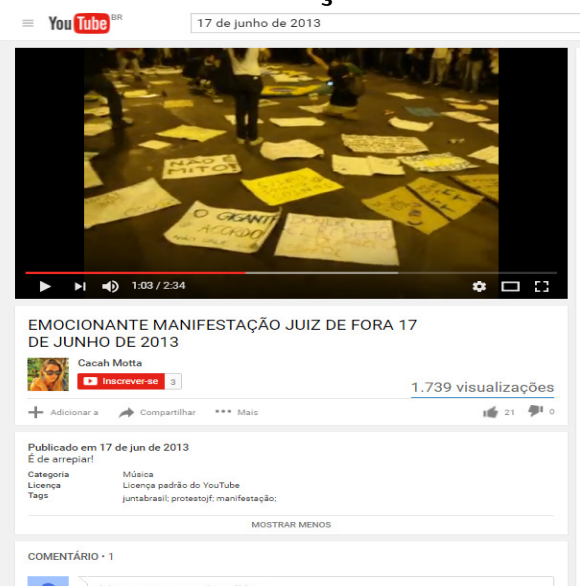

Fonte: YouTube.com - 2016

Os aproximados 145 mil vídeos puderam ser apresentados mediante essa busca, por meio do atributo da folksonomia, que permitiu que cada usuário pudesse etiquetar seu vídeo com várias tags, e dentre elas, uma etiqueta comum. Se durante o upload do vídeo o ambiente YouTube exigisse uma taxonomia, os vídeos que possuíssem alguma etiqueta diferente não seriam colocados na lista, como foram colocados, por exemplo, vídeos da manifestação em São Paulo, Rio de Janeiro e Juiz de Fora. Além de listar todos os vídeos com a sentença "17 de junho de 2013", a folksonomia encontrada no website permite hiperlinks nas tags (fig.4), o que leva a outros vídeos também etiquetados. 
Figura 4 - Hiperlinks nas tags

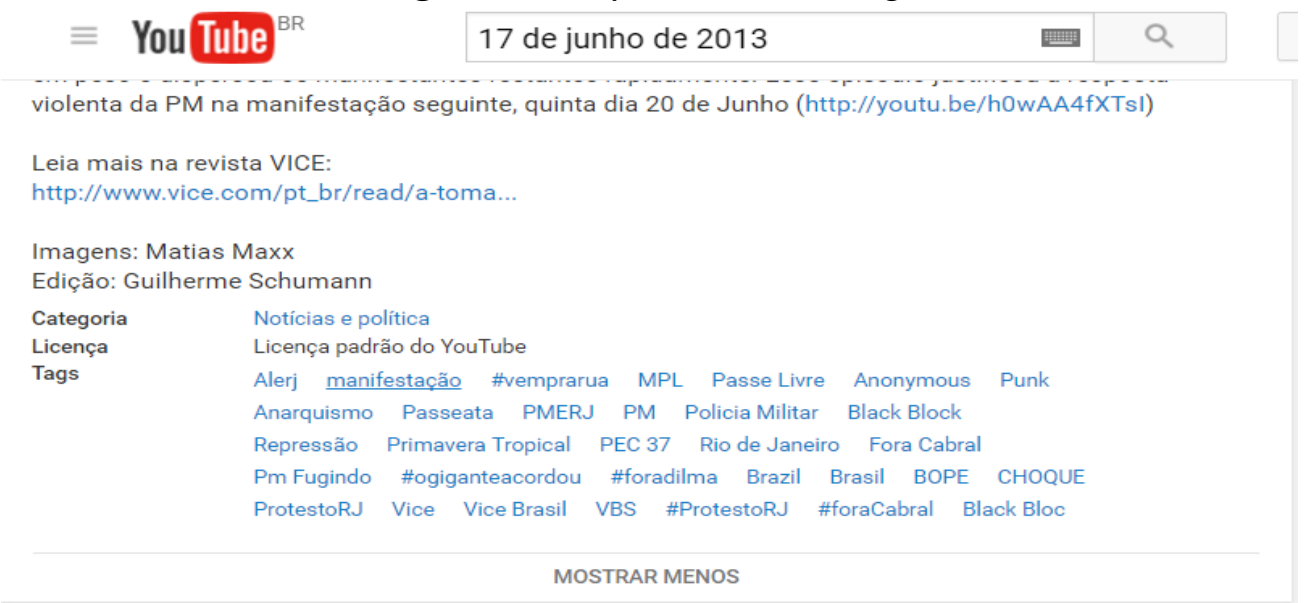

Fonte: YouTube.com - 2016

Ao clicar em um dos hiperlinks, o usuário é automaticamente direcionado a página inicial do YouTube, com o campo de busca preenchido pelo nome da tag. Ao clicar em "manifestação", somos levados a seguinte página (fig.5):

Figura 5 : (Tag) Manifestação

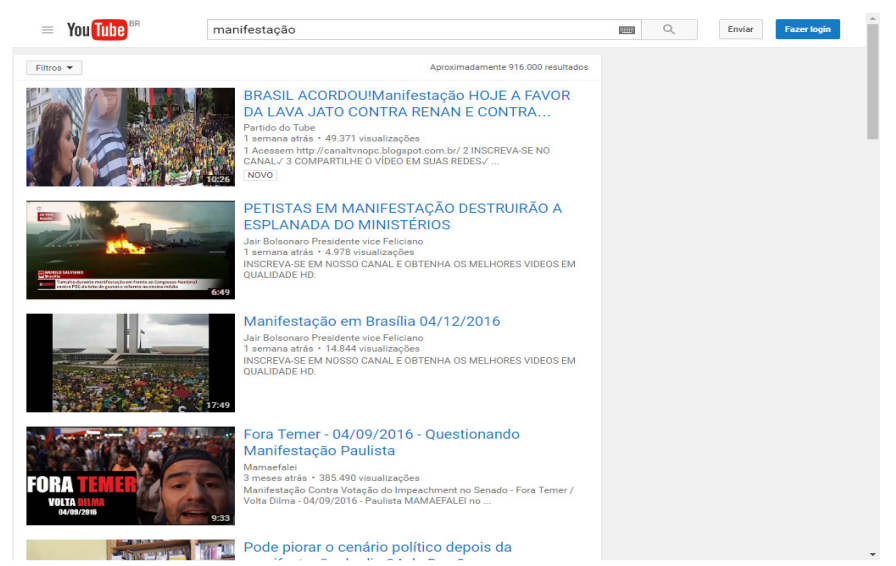

Fonte: YouTube.com - 2016

Além deste recurso, é possível ainda encontrar mais vídeos, de acordo com os relacionados, apresentados no canto direito do vídeo. Esses vídeos seguem a mesma linha da etiquetagem social: possuem termos, títulos e tags comuns, como pode ser observado na Figura 6. 
Figura 6 - Vídeos relacionados

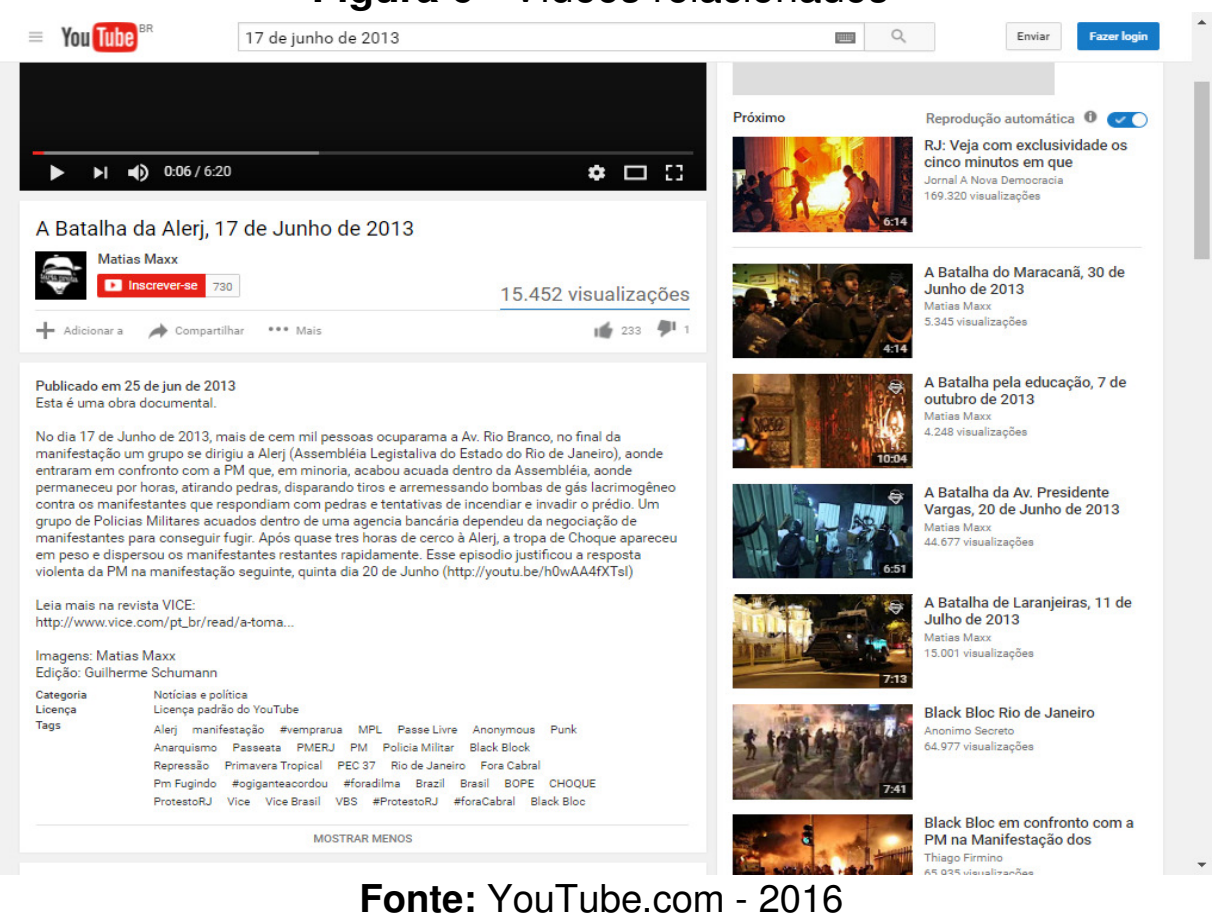

Ao analisarmos três vídeos apresentados nas recomendações, foi possível encontrar algumas semelhanças nas folksonomias apresentadas. Os três vídeos são sobre protestos ocorridos no ano de 2013, no Rio de Janeiro - como o vídeo que os relacionou. Suas etiquetas são parecidas, e eles foram postados pelo mesmo usuário, utilizando a palavra "A Batalha" no título (fig. 7).

\section{Figura 7 Folksonomia semelhante nas tags e título.}
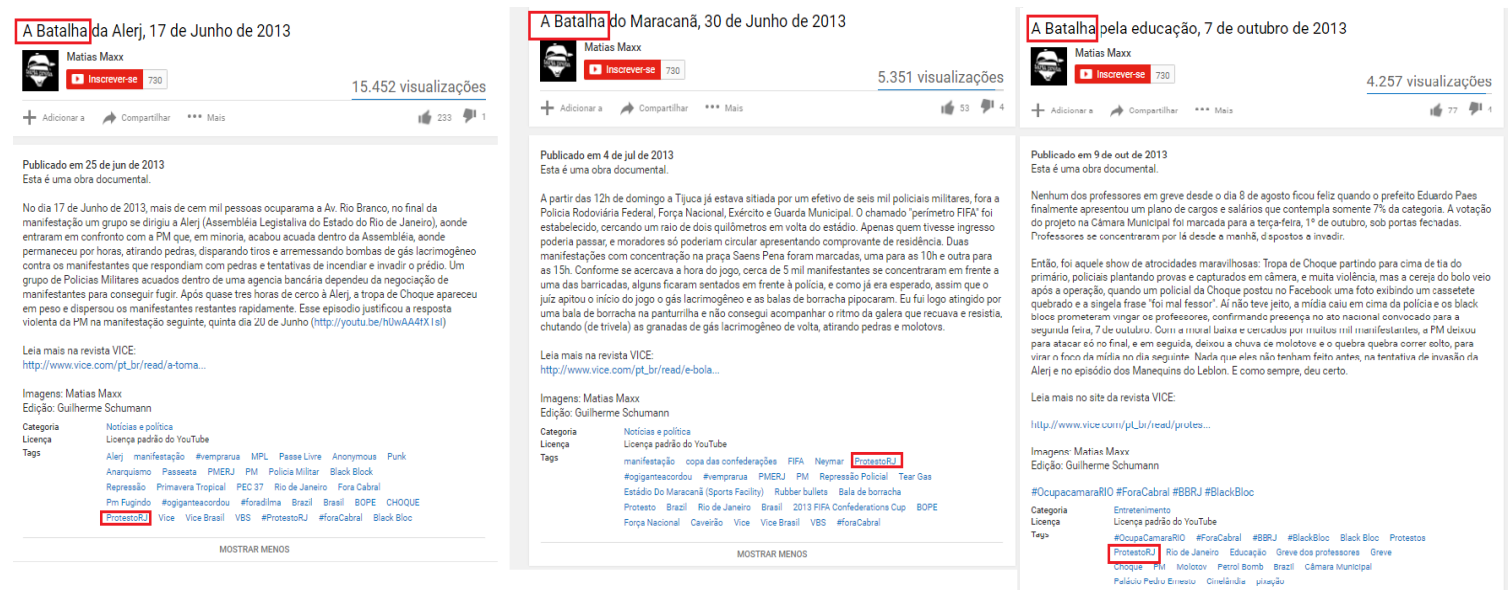

Fonte: YouTube.com - 2016

Dos vídeos apresentados, dois não são sobre os protestos do dia 17 de junho de 2013. Ainda assim, o assunto que foi classificado se mostra o mesmo nos três vídeos: eles seguem a mesma temática, e de acordo com as tags aplicadas através 
da folksonomia, é possível navegar por um extenso leque de vídeos, cujo conteúdo é pertencente à mesma temática.

De volta a página com o resultado das buscas para 17 de junho de 2013, é possível navegar por vídeos com o mesmo tema até a página 8 - sendo o último vídeo diferente dos demais, com outra temática, como pode ser observado na figura 8 a seguir.

Figura 8 - Resultados da busca até a página 8

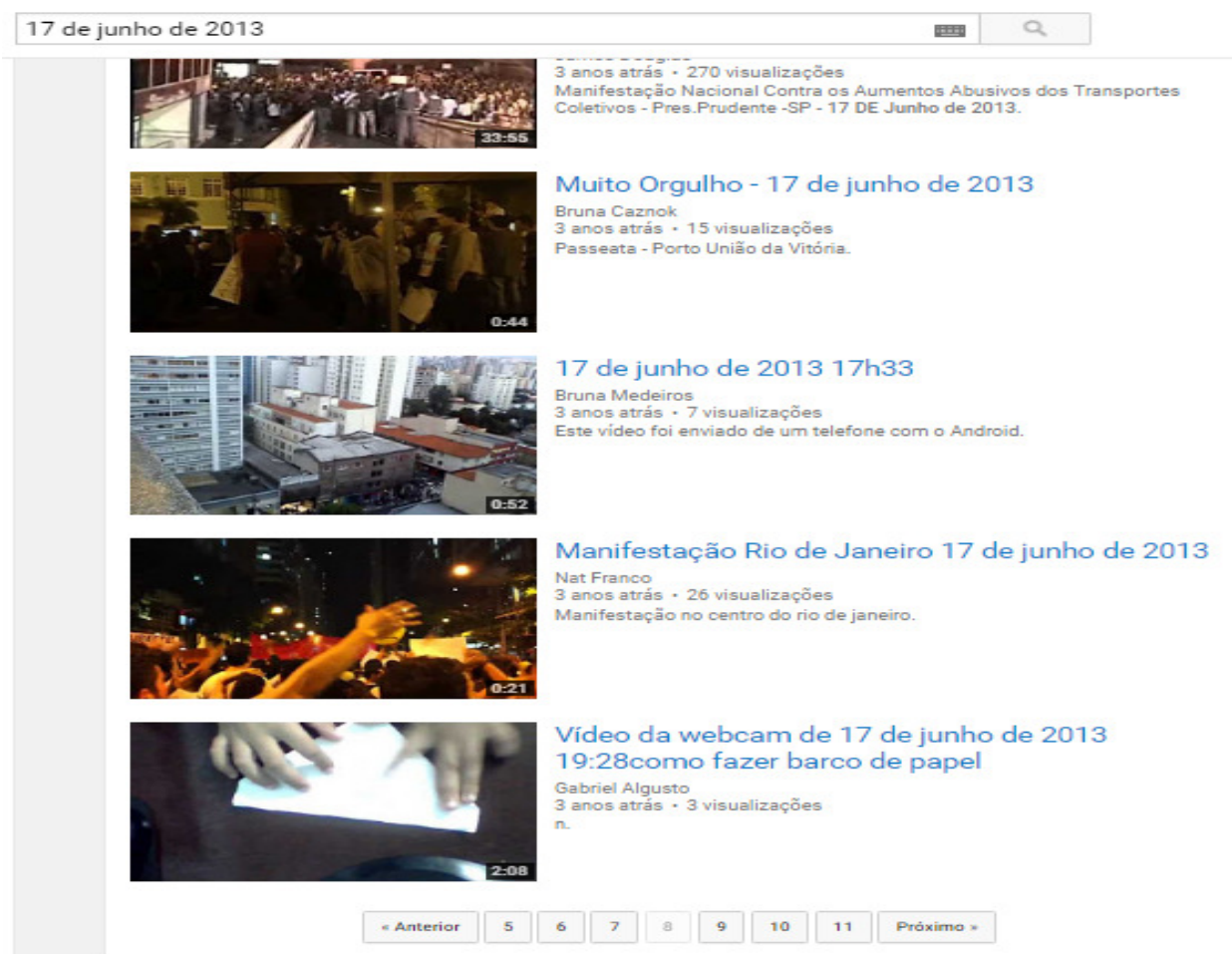

Fonte: YouTube.com - 2016

Os resultados a partir da página 9 apresentam vídeos com temáticas distintas, onde apenas o título possui uma indicação no título, possuindo "17" "junho" ou "2013" em seu título. As tags também apresentam conteúdo diverso, não mais possuindo palavras como "manifestação", "protesto" ou "17 de junho de 2013".

\section{CONSIDERAÇÕES FINAIS}

Ao analisarmos o conceito de Encontrabilidade da Informação desenvolvido por Vechiato e Vidotti (2014a, p. 164), nos deparamos com a afirmação de que ela "[...] sustenta-se fundamentalmente na interseção entre as funcionalidades de um ambiente informacional e as características dos sujeitos informacionais." Assim, ao analisarmos o ambiente informacional YouTube, buscamos compreender como a 
informação está disposta naquele ambiente de acordo com a etiquetagem social - a folksonomia.

No âmbito da Encontrabilidade da Informação, as folksonomias estão relacionadas à organização social da informação e propiciam ao sujeito a classificação de recursos informacionais (no caso do ambiente estudado, vídeos), bem como encontrar a informação por meio da navegação e do mecanismo de busca.

No ambiente escolhido, é possível utilizar a folksonomia no momento da publicação do vídeo: o título, a descrição e as tags de cada vídeo podem ser colocadas pelo usuário, sem obedecer qualquer tipo de regra, apenas seguindo a intenção do usuário.

Ao utilizarmos o mecanismo de busca, foi inserida a sentença "17 de junho de 2013", com a intenção de encontrar material de videoativismo referente aos protestos ocorridos nesta data. A busca retornou aproximadamente 145 mil vídeos com o tema proposto.

Esses vídeos são apresentados em uma página de resultados, que apresenta o título, uma miniatura e breve descrição. Neste primeiro contato, é possível visualizar os 20 primeiros vídeos, e os outros são apresentados nas páginas seguintes. Após a análise, foram encontradas 8 páginas com vídeos que falam realmente sobre o tema buscado, totalizando assim 159 vídeos sobre o tema, e 1 aleatório.

Após busca, foram analisados alguns vídeos, para que fossem encontradas as folksonomias. Nos resultados das primeiras 8 páginas, pode-se avaliar a influência desse atributo para a Encontrabilidade da Informação.

$\mathrm{Na}$ primeira página, todos os vídeos apresentavam a sentença completa em seu título e/ou descrição. As tags - que podem ser vistas ao clicar em "mostrar mais" na descrição dos vídeos, apresentavam termos semelhantes - nem sempre "17 de junho de 2013", porém, os mesmos termos puderam ser encontrados em vídeos diferentes, como "manifestação" na figura 2 e 3.

As mesmas possuem hiperlink, o que facilita o uso do atributo das folksonomia, pois através deste, é possível encontrar mais vídeos sobre o tema, ou vídeos semelhantes. Além deste recurso de hiperlinks nas tags, é possível também encontrar mais vídeos através do sistema de recomendação que o ambiente possui, 
levando o usuário a navegar por mais vídeos que podem conter a mesma temática, tag ou título, como visto na figura 7.

Assim, foi possível analisar que os vídeos sobre essa manifestação refletem este novo panorama midiático, informacional, cultural, social e político, no qual a população ganha mais liberdade de comunicação e autonomia para a classificação das suas informações na rede.

Identificamos que o videoativismo e suas conexões em rede por meio do ambiente informacional estudado, foi amplamente divulgado e alcançou um público maior do que o mesmo assunto divulgado pela mídia oficial, por possuir um dos atributos da Encontrabilidade da Informação: as folksonomias.

De acordo com Castells (2013), os movimentos sociais em rede são amplamente fundamentados na internet, que é uma plataforma privilegiada para a construção social da autonomia. Tais movimentos, assim como os demais da história, trazem a marca de sua sociedade. No caso dos atuais, são largamente constituídos por indivíduos que convivem confortavelmente com as tecnologias digitais no mundo híbrido da realidade virtual - isto, atrelado ao fato de o usuário possuir o domínio da etiquetagem no ambiente, favorece a Encontrabilidade da Informação.

\section{REFERÊNCIAS}

ASSIS, J. de; MOURA, M. A. Folksonomia: a linguagem das tags. Encontros bibli: Revista Eletrônica de Biblioteconomia e Ciência da Informação, v. 18, n. 36, p. 85106, jan./abr. 2013.

BARDAJÍ, L. L. Rodea el Congreso: la confrontación simbólica através del audiovisual. In: BUSTOS, Gabriela et al. Videoactivismo - acción política, cámara en mano. Tenerife: Cuadernos Latina, 2014.

BLATTMANN, U.; SILVA, Fabiano Couto Corrêa da. A Colaboração e a interação na Web 2.0. Revista ACB: Biblioteconomia em Santa Catarina, Florianópolis, v. 12, n. 2, p. 191-215, jul./dez., 2007.

CASTELLS, M. Redes de Indignação e Esperança: Movimentos Sociais na Era da Internet. Rio de Janeiro: Editora Zahar, 2013.

CATARINO, M. E.; BAPTISTA, A. A. Folksonomia: um novo conceito para a organização dos recursos digitais na web. DataGramaZero, v. 8, n. 3, 2007. Disponível em: <http://basessibi.c3sl.ufpr.br/brapci/v/a/4483>. Acesso em: 04 set. 2017. 
DURIGAN, G. Vídeo-ativismo em rede: um estudo sobre os protestos brasileiros de 2013 registrados no documentário 20 centavos. 2016. 102f. Dissertação (Mestrado em Mídia e Tecnologia) - Universidade Estadual Paulista "Júlio de Mesquita Filho", Faculdade de Arquitetura, Artes e Comunicação, Bauru, 2016.

FAROOQ et al. Evaluating tagging behavior in social bookmarking systems: metrics and design heuristics. In: CONFERENCE ON SUPPORTING GROUP WORK. p. 351-360, 2007. Proceedings..., 2007.

GARCIA, P. F. Videoactivismo de convocatoria: el linguaje publicitario en las Mareas Ciudadanas. In: BUSTOS, Gabriela et al. Videoactivismo - acción política, cámara en mano. Tenerife: Cuadernos Latina, 2014.

LOHMANN, S.; DÍAZ, P. Representing and visualizing folksonomies as graphs A reference model. 2012 International Working Conference on Advanced Visual Interfaces, AVI 2012, Capri Island. p. 729-732.

MAZETTI, H. Resistências criativas: os coletivos artísticos e ativistas no Brasil. Revista Lugar Comum, n. 25-26, 2008.

MIKA, P. Social networks and the semantic web. New York: Springer, 2007. 234 p.

MORVILLE, P. Libraries at the crossroads of ubiquitous computing and the internet. Online, v. 29, n. 6, nov./dez. 2005.

REIS, L. F. M. dos. Sistema de Recomendação Baseado em Conhecimento. 110 f. 2012. Dissertação (Mestrado em Engenharia Informática) - Departamento de Engenharia Informática Faculdade de Ciências e Tecnologia, Universidade de Coimbra, Coimbra, 2012.

RENÓ, D. P. Folkcomunicación ciudadana a partir de la web 2.0 y de la movilidad. Revista internacional de Comunicación y Desarrollo, v. 1, p. 51-59, 2015.

RIBEIRO, O. B.; VIDOTTI, S. A. B. G. Otimização do acesso à informação científica: discussão sobre a aplicação de elementos da arquitetura da informação em repositórios digitais. Biblos, v. 23, n. 2, p. 105-116, 2009.

ROBREDO, J. Sobre arquitetura da informação. Revista Ibero-americana de Ciência da Informação, v. 1, n. 2, p. 115-137, 2008.

SHEN, K.; WU, L. Folksonomy as a complex network. 2005.

TSUI, E.; et al. A concept-relationship acquisition and inference approach for hierarchical taxonomy construction from tags. Information Processing and Management, v. 46, n.1, p. 44-57, 2010.

VECHIATO, F. L.; OLIVEIRA, H. P. C. de; VIDOTTI, S. A. B. G. Arquitetura da informação pervasiva e encontrabilidade da informação: instrumento para a avaliação de ambientes informacionais híbridos. In: ENCONTRO NACIONAL DE PESQUISA EM CIÊNCIA DA INFORMAÇÃO (ENANCIB), 17., 2016, Salvador. Anais...Salvador: ENANCIB, 2016. 
VECHIATO, F.; VIDOTTI, S. A. B. G. Encontrabilidade da Informação: atributos e recomendações para ambientes informacionais digitais. In: ENCONTRO NACIONAL DE PESQUISA EM CIÊNCIA DA INFORMAÇÃO (ENANCIB), 15., 2014. Belo Horizonte. Anais... Belo Horizonte, ENANCIB, 2014b.

VECHIATO, F. L.; VIDOTTI, S. A. B. G. Encontrabilidade da informação. 1. ed. São Paulo: Cultura Acadêmica, 2014a. (Coleção PROPG Digital- UNESP). Disponível em: <http://hdl.handle.net/11449/126218>. Acesso em: 04 set. 2017.

WURMAN, R. S. Ansiedade de Informação: como transformar informação em compreensão. São Paulo: Cultura, 2003.

WURMAN, R. S. Ansiedade de informação 2: um guia para quem comunica e dá instruções. São Paulo: Editora de Cultura, 2005.

\title{
FINDABILITY AND VIDEOTIVISM: AN ANALYSIS OF THE FOLKSONOMY ATTRIBUTE ON YOUTUBE
}

\begin{abstract}
Introduction: Digital technologies associated with mobility and the social web have transformed social relations into several spheres. Environments have become more and more cooperative and the mass of information deposited and shared daily grows according to the number of users - which has modified the relation that we have with the form of sharing the information in the web, as well as the form that we produce, or we carry out any type of social manifestation. Objective: According to this premise, this article presents a study that sought to analyze the folksonomy - attribute of the Information Findability of Vechiato and Vidotti (2014), which analyzes the social labeling - starting from the users. Methodology: The analysis was performed in the YouTube environment, collecting the information about the protests of July 17, 2013 and identifying the content of videoativism to understand how the attribute contributes to the application of Information Findability. Results: On YouTube, approximately 145,000 search results for "June 17, 2013" are presented, and most do not belong to the traditional media - videotaped proposals are proposed. Of these, after analysis according to the methodology of observation, the number has been reduced to 8 pages of relevant content. Conclusion: It was possible to use folksonomy at the time of publication of the video. With the search "June 17, 2013", and the result was 145 thousand videos. After using the information, this number changed to 159 videos that have real connection with the proposed theme - which classifies the folksonomy attribute as quite relevant for the Findability in the studied environment.
\end{abstract}

Descriptors: Information Findability. Folksonomy. Videotaping. 


\section{ENCONTRABILIDAD DE LA INFORMACIÓN Y VIDEOTIVISMO: UN ANÁLISIS DEL ATRIBUTO FOLKSONOMIA NO YOUTUBERESUMEN}

Introducción: Las tecnologías digitales asociadas a la movilidad y la web social han transformado las relaciones sociales en diversas esferas. Los ambientes se han vuelto cada día más cooperativos y la masa de información depositada y compartida diariamente crece de acuerdo con el número de usuarios, lo que ha modificado la relación que tenemos con la forma de compartir la información en la web, así como la forma que producimos o realizamos cualquier tipo de manifestación social. Objetivo: En este artículo se presenta un estudio que buscó analizar la folksonomía-atributo de la Encontrabilidad de la Información de Vechiato y Vidotti (2014), que analiza el etiquetado social - partiendo de los usuarios. Metodología: El análisis fue realizado en el ambiente YouTube, recogiendo las informaciones sobre las protestas del día 17 de julio de 2013 e identificando el contenido de videoactivismo para comprender de qué forma el atributo aporta contribución a la aplicación de la Encontrabilidad de la Información. Resultado: En YouTube, se presentan aproximadamente 145 mil resultados con la búsqueda "17 de junio de 2013", y en su mayoría, no pertenecen a los medios tradicionales - son propuestas videoativistas. De estos, después de un análisis de acuerdo con la metodología de observación, el número se redujo a 8 páginas de contenido relevantes. Conclusión: Fue posible utilizar la folksonomía en el momento de la publicación del vídeo. Con la búsqueda "17 de junio de 2013", y el resultado fue 145 mil vídeos. Después de la utilización de la información, este número ha cambiado a 159 videos que tienen verdadera relación con el tema propuesto - que clasifica el atributo folksonomía como bastante relevante para la Encontrabilidad en el ambiente estudiado.

Descriptores: Encontrabilidad de la información. Folksonomía. Videoactividad.

Recebido: 20.10 .2017

Aceito: 28.12.2017

Inf. Prof., Londrina, v. 6, n. 2, p. $60-76$, jul./dez. 2017

http://www.uel.br/revistas/infoprof/ 